F. Reprod. Fert. (1970) 22, 385-398

\title{
FERTILITY OF RAM SPERMATOZOA FROZEN BY THE PELLET METHOD
}

\section{TRANSPORT AND VIABILITY OF SPERMATOZOA WITHIN THE GENITAL TRACT OF THE EWE}

\author{
R. J. LIGHTFOOT* AND S. SALAMON
}

Department of Animal Husbandry, University of Sydney, Sydney, N.S.W. 2006

\section{(Received 27th May 1969)}

Summary. The transport of fresh and frozen spermatozoa through the genital tract of the ewe was studied in four experiments.

1. Extremely low numbers of spermatozoa were recovered from the Fallopian tubes of ewes after insemination with either fresh (diluted) or frozen spermatozoa when both were used at a concentration of $0.4 \times 10^{9}$ motile spermatozoa $/ \mathrm{ml}$, but the fertilization rate was higher with the fresh semen. High doses of oxytocin did not affect sperm transport, but significantly depressed the fertilization rate.

2. Concentrating the thawed semen before insemination resulted in increased numbers of spermatozoa recovered from the Fallopian tubes. Fresh semen resulted in even higher numbers in the tubes and an increased proportion of ova recovered with spermatozoa on the zona pellucida.

3. Ewes were slaughtered $30 \mathrm{~min}$ after insemination with either fresh or frozen semen of varying concentration. The number of spermatozoa recovered from the cervix after insemination with frozen semen was dependent upon the concentration of motile spermatozoa in the inseminate. At equal concentration, fresh semen was superior to frozen semen.

4. Uterine insemination at varying periods before ovulation showed that a proportion of the pellet-frozen spermatozoa survived in the genital tract with retention of fertilizing ability for 18 to $35 \mathrm{hr}$.

\section{INTRODUCTION}

The infertility that normally accompanies insemination of ewes with frozen ram semen has been well documented (see reviews by Emmens, 1961; Emmens \& Robinson, 1962; Sadleir, 1966), but until recently, little research has been conducted to investigate the reasons for the low fertility. Lopyrin \& Loginova (1958) have reported that frozen ram spermatozoa penetrate more slowly to the cranial cervix than do those from fresh semen but the authors do not provide figures to substantiate this claim. Support for the theory of inadequate sperm transport is seen in the results of Loginova (1962), who was unable to recover any fertilized eggs from eight ewes following cervical insemination,

\footnotetext{
* Present address: Department of Agriculture, South Perth, Western Australia 6151.
} 
whereas all three ewes examined after tubal insemination yielded fertilized eggs.

More recently, Salamon \& Lightfoot (1967) found very low numbers of spermatozoa in the Fallopian tubes and a low fertilization rate following normal cervical insemination with pellet-frozen ram semen. When the cervix was by-passed by uterine insemination, however, fertilization rates of 88 and $93 \%$ were obtained. Similarly, Loginova \& Zeltobrjuk (1968) have reported obtaining fertilization in two of sixteen and fifteen of seventeen ewes following cervical and tubal insemination, respectively. Working with ram semen frozen by the conventional slow freezing technique, Mattner, Entwistle \& Martin (1969) studied the distribution of spermatozoa throughout the genital tract of ewes slaughtered either 4 or $24 \mathrm{hr}$ after cervical insemination. They found comparatively few spermatozoa throughout the tract at $4 \mathrm{hr}$, while by $24 \mathrm{hr}$ there were none in the uterus or Fallopian tubes and very few in the cervix. Both Loginova \& Zeltobrjuk (1968) and Mattner et al. (1969) attributed the poor results with frozen semen to reduced viability of the spermatozoa in vivo.

The experiments reported here were conducted to examine more fully the transport and viability of frozen spermatozoa in the genital tract of the ewe, and in particular their early entry into the cervix.

\section{MATERIALS AND METHODS}

\section{Experimental designs}

Details of design and treatment comparisons for each of the four experiments are presented in Experimental Design and Results.

\section{Sheep and management}

Mature Merino ewes were used in all experiments, and were allocated at random to treatment groups on a within-draft basis. Oestrous ewes were detected with vasectomized rams fitted with Sire-sine harnesses and crayons (Radford, Watson \& Wood, 1960). All vasectomized rams were previously tested by electro-ejaculation to ensure the absence of spermatozoa in the ejaculate.

In Exps 1, 2, 3 and 4b, the ewes were inseminated either during a natural cyclic oestrus or at the second oestrus after synchronization with intravaginal sponges (Syncro-Mate, Searle) impregnated with Cronolone (Robinson, 1965).

Experiment 4a was conducted in October, a season when most ewes at the location concerned are usually in anoestrus. The ewes were therefore injected intramuscularly (i.m.) with 1000 i.u. (reputed) pregnant mare serum gonadotrophin (G. D. Searle, Batch no. 2481) on the day of intravaginalsponge withdrawal, and the ewes were inseminated at the resultant oestrus. The PMSG was subsequently assayed and found to be 2.2 times the stated potency, so, in fact, a dose of approximately 2200 i.u. was inadvertently administered.

\section{Semen}

Semen was collected from mature Merino rams by artificial vagina. For freezing, ejaculates of good initial motility were pooled and diluted $1: 1$ (Exp. 1) or 1:3(Exps 2, 3 and 4 ) at $30^{\circ} \mathrm{C}$ with a diluent consisting of 166.5 
mu-raffinose-102 mm-sodium citrate and $15 \%(\mathrm{v} / \mathrm{v})$ egg yolk to which glycerol $(6 \% \mathrm{v} / \mathrm{v}$, Exp. 1; 5\%, Exps 2 to 4$)$ was added. The diluted semen was cooled to $5^{\circ} \mathrm{C}$ over a period of $1 \frac{1}{2} \mathrm{hr}$, then held at that temperature for an additional 3 to $6 \mathrm{hr}$ before pellet-freezing $(0.035 \mathrm{ml}$, Exps 1 and $4 \mathrm{a} ; 0.35 \mathrm{ml}$, Exps 2, 3 and $4 \mathrm{~b})$ on dry ice. The pelleted semen was stored in liquid nitrogen for 2 to 12 weeks before use. Pellets were thawed in test tubes containing $88.4 \mathrm{~mm}$-sodium citrate (2 : 1, pellets: thawing solution, $\mathrm{v} / \mathrm{v}$; in Exp. 1) or in $80.6 \mathrm{~mm}$-sodium citrate-44.4 mm-glucose solution ( $1: 3$, Exps 2, 3 and 4) held in a water bath at $37^{\circ} \mathrm{C}$. In the latter experiments, the thawed semen was centrifuged at 2500 $\mathrm{rev} / \mathrm{min}$ for $15 \mathrm{~min}$ and the supernatant discarded to give the concentration of motile spermatozoa required for insemination.

For fresh semen, ejaculates of good initial motility were pooled then diluted to the required concentration of motile spermatozoa using either egg yolkglucose-citrate (15\%, v/v, 44.4 and $80.6 \mathrm{~mm}$ respectively) or, in Exp. 1, yolkraffinose-citrate diluent. The concentration of both fresh and frozen semen was determined by haemocytometer, and the percentage motile spermatozoa by visual assessment $(\times 300)$ under a coverslip on a warm stage.

\section{Insemination}

Cervical inseminations (Exps 1,2 and 3) were performed with the aid of a duck-billed speculum and headlight, the semen being deposited just inside or among the folds of the external cervical os. Particular care was taken in Exp. 3 to achieve a uniform 0.5 to $1.0 \mathrm{~cm}$ depth of insemination.

Uterine inseminations (Exp. 4) were performed following mid-ventral laparotomy under local anaesthesia. Semen was deposited into the cranial ipsilateral uterine horn by means of a sterile glass pipette with a fine glazed tip.

\section{Oxytocin}

The effect of oxytocin (Syntocinon, Sandoz) on the transport of spermatozoa and the fertilization of eggs was studied in Exp. 1. It was injected in physiological saline $(1 \mathrm{ml}, \mathrm{i} . \mathrm{m}$.) into the hind leg at the time of insemination.

\section{Recovery and counting of spermatozoa}

Spermatozoa were recovered by flushing with physiological saline the appropriate regions of the genital tract of ewes under general anaesthesia (Exp. 1), local anaesthesia with sedation (Exp. 2), or following slaughter and removal of the genital tract (Exp. 3). The techniques used for recovery and counting of spermatozoa from the Fallopian tubes were as described by Quinlivan \& Robinson (1967) for recovery and Mattner \& Braden (1963) for counting, except that an eosin-fast green F.C.F. stain (Hackett \& Macpherson, 1965) was used for staining the flushings before counting.

Ewes in Exp. 3 were killed $30 \mathrm{~min}$ after insemination by intra-cardiac injection of sodium pentobarbitone solution $(5 \mathrm{ml}, 600 \mathrm{mg} / \mathrm{ml})$ and the genital tract was removed immediately after ligation of the utero-tubal and uterocervical junctions. The Fallopian tubes and uteri were flushed with saline ( 1.5 and $20 \mathrm{ml}$ respectively) and, after removal of the cervix, the vagina was flushed 
using a funnel to collect the washings. Extreme care was taken, with precautions similar to those adopted by Mattner \& Braden (1963), to avoid contamination of flushings with spermatozoa from other regions. The flushings were frozen $\left(-15^{\circ} \mathrm{C}\right)$ and stored for subsequent counting of spermatozoa.

The cervices were separated from the remainder of the tract within $5 \mathrm{~min}$ of slaughter and were frozen rapidly by suspension in liquid nitrogen vapour, then stored at $-15^{\circ} \mathrm{C}$. For counting spermatozoa, each cervix was cut transversely, using a new scalpel blade, into equal caudal, mid and cranial segments while still frozen. Each segment was then cut longitudinally into six slivers which were placed in a new vial containing $10 \mathrm{ml}$ of physiological saline. When thawing was complete, the vials were allowed to stand for a further 30 min, and were shaken vigorously before samples were withdrawn for counting spermatozoa by the standard slide technique.

\section{Egg recovery and fertilization}

In Exps 1 and 4, eggs were recovered 48 to $60 \mathrm{hr}$ after insemination (Nembutal anaesthesia, Exp. 1; local anaesthesia plus sedation, Exp. 4) and examined for cell cleavage. In Exp. 2, tubal flushings from ewes in which ovulation had occurred were examined before freezing and the numbers of spermatozoa on the zona pellucida of recovered eggs were recorded.

\section{Statistical analyses}

The statistical significance of treatment comparisons on the numbers of spermatozoa recovered from the genital tract (Exps 1a, 2 and 3) were determined by analysis of variance after transformation of the data according to the formula $\log _{10}(n+2)$. Arithmetic means are presented in the tables.

The effects of treatments on the proportions of eggs and ewes fertilized (Exps $1 \mathrm{~b}$ and $4 \mathrm{a}$ ) and on the distribution of fertilized eggs according to the number of spermatozoa on the zona pellucida (Exp. 4a) were in each case examined by analysis of $\chi^{2}$ (Claringbold, 1961).

\section{EXPERIMENTAL DESIGN AND RESULTS}

\section{EXPERIMENT 1}

The effects of oxytocin and of insemination with fresh or frozen semen on the number of spermatozoa recovered from the Fallopian tubes and on fertilization were examined in Exp. 1. Exps 1a and 1b were conducted concurrently using the same flock of ewes and rams and the same insemination procedures.

\section{Experiment 1a. Spermatozoa in the Fallopian tubes}

The experiment was of factorial design: $2 \times 4 \times 3 ; n=3, N=72$.

(1) Semen type-fresh versus frozen

(2) Dose of oxytocin-0 versus 10 versus 20 i.u., i.m., at the time of insemination

(3) Time of flushing Fallopian tubes-3 versus 6 versus 12 versus $24 \mathrm{hr}$ postinsemination.

Each ewe was inseminated once (cervical insemination) 10 to $25 \mathrm{hr}$ after the 
onset of oestrus with $0.3 \mathrm{ml}$ of semen containing $120 \times 10^{6}$ motile spermatozoa.

Table 1 shows the number of ewes from which spermatozoa were recovered and the mean numbers of spermatozoa/ewe according to treatments. Overall, spermatozoa were recovered from $72 \%$ of the ewes but the numbers recovered were generally low, none of the factors studied had a statistically significant effect, and there were no interactions.

TABLE 1

THE MEAN NUMBERS OF SPERMATOZOA RECOVERED FROM THE FALLOPIAN TUBES AFTER CERVICAL INSEMINATION

\begin{tabular}{l|c|c}
\hline \multicolumn{1}{c|}{ Treatment } & $\begin{array}{c}\text { No. of ewes from } \\
\text { which spermatozoa } \\
\text { were recovered }\end{array}$ & $\begin{array}{c}\text { Mean no. of } \\
\text { spermatozoa } \\
\text { lewee }\end{array}$ \\
\hline $\begin{array}{l}\text { (1) Type of semen }(\mathrm{n}=36) \\
\text { Fresh } \dagger\end{array}$ & \\
Frozen $\dagger$ & 23 & 62 \\
$P$ & 29 & 78 \\
(2) Time of recovery in hr after insemi- & $\mathrm{NS}$ & $\mathrm{NS}$ \\
nation $(\mathrm{n}=18)$ & & \\
3 & & \\
6 & 13 & 103 \\
12 & 13 & 44 \\
24 & 13 & 53 \\
$P$ & 13 & $\mathrm{NS}$ \\
(3) Dose (i.u.) of oxytocin $(\mathrm{n}=24)$ & $\mathrm{NS}$ & \\
0 & 19 & 52 \\
10 & 17 & 60 \\
20 & 16 & 99 \\
$P$ & $\mathrm{NS}$ & $\mathrm{NS}$ \\
\hline
\end{tabular}

$\mathrm{n}=$ Number of ewes per comparison.

$\dagger$ Inseminate volume $=0.3 \mathrm{ml}$ containing $120 \times 10^{6}$ motile spermatozoa $\left(0.4 \times 10^{9} / \mathrm{ml}\right)$.

\section{Experiment 1b. Fertilization}

The experiment was of factorial design: $2 \times 3 ; \mathrm{n}=9$ to 16 (number of ewes from which eggs were recovered), $\mathrm{N}=70$.

(1) Semen type-fresh versus frozen

(2) Dose of oxytocin-0 versus 10 versus 20 i.u., i.m. at the time of insemination.

The results are presented in Table 2. In all, eighty-eight ewes were inseminated and of these, seventy $(80 \%)$ subsequently yielded a total of eightyfour eggs. There were no treatment effects upon the proportions either of eggs recovered or ewes from which eggs were recovered. Only twenty-two of the eighty-four eggs were fertilized $(26 \cdot 2 \%)$. Insemination with fresh semen resulted in seventeen fertilized eggs of thirty-eight eggs recovered, and with frozen semen in five of forty-six $(44.7$ versus $10.9 \% ; P<0.001)$. The administration of oxytocin significantly depressed the percentage of eggs fertilized and of ewes which yielded fertilized eggs $(P<0 \cdot 05)$. Of the ewes that were not injected with oxytocin, fertilized eggs were recovered from $45.5 \%$ (five/eleven) and $31.3 \%$ (five/sixteen) following insemination with fresh and frozen spermatozoa respectively. 


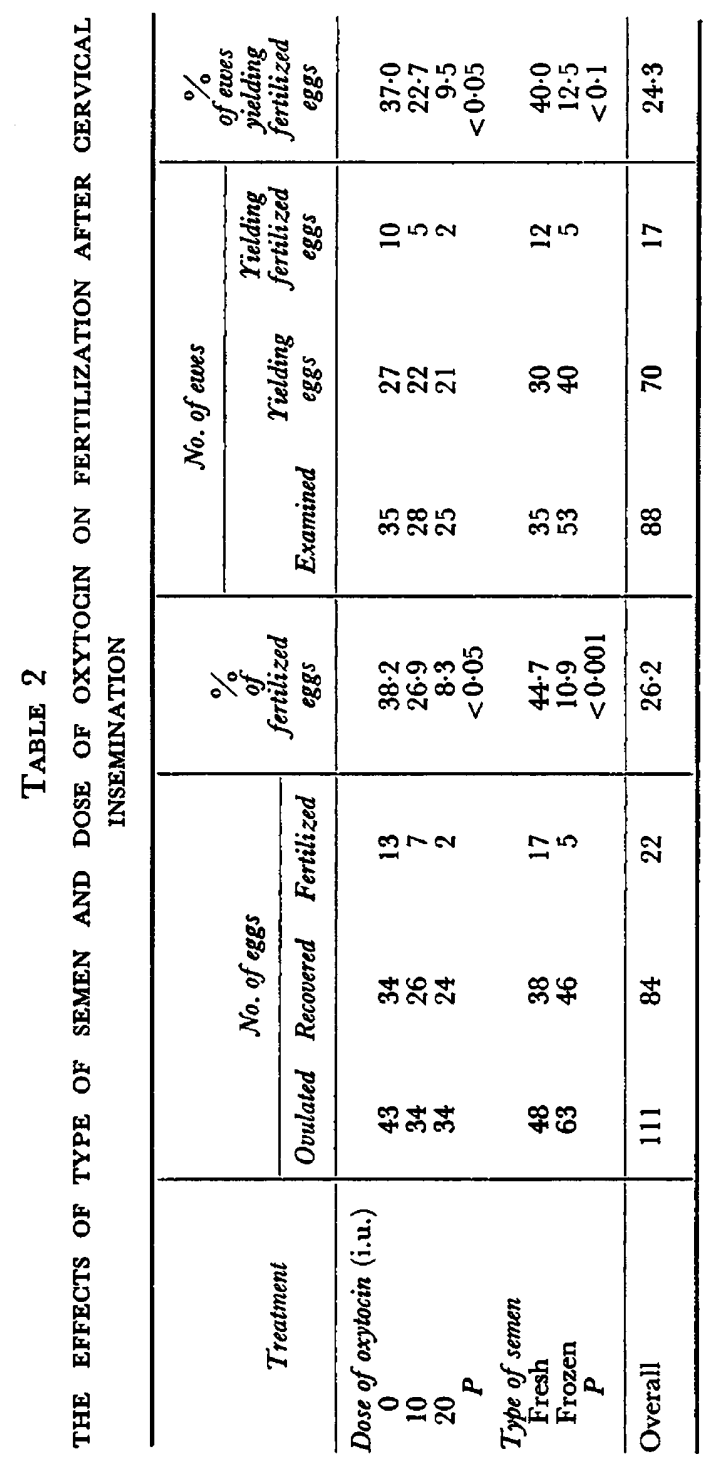




\section{EXPERIMENT 2}

The effects of type of semen (fresh versus frozen) and of concentration of motile spermatozoa in frozen semen on the number of spermatozoa recoverable from the Fallopian tubes $24 \mathrm{hr}$ after insemination were examined in Exp. 2.

There were three treatment groups, each of fourteen ewes; $N=42$ :

(1) - Frozen semen, $0.8 \times 10^{9}$ motile spermatozoa $/ \mathrm{ml}$

(2)-Frozen semen, $1.6 \times 10^{9}$ motile spermatozoa $/ \mathrm{ml}$

(3)-Fresh semen, $1.6 \times 10^{9}$ motile spermatozoa $/ \mathrm{ml}$

Each ewe was inseminated once (cervical insemination) with $0.1 \mathrm{ml}$ of semen, 1 to $16 \mathrm{hr}$ after the onset of oestrus.

The results are presented in Table 3. Spermatozoa were recovered from the Fallopian tubes of eighteen $(64.3 \%)$ of the twenty-eight ewes examined $24 \mathrm{hr}$ after insemination with frozen semen, whereas all fourteen ewes inseminated with fresh semen yielded spermatozoa $(P<0.05)$. The mean numbers of spermatozoa recovered were 7741 and 575 for ewes inseminated with fresh and frozen semen respectively $(P<0 \cdot 01)$. There was no significant effect of concentration of motile spermatozoa in the frozen semen.

There was an apparent relationship between the percentage of eggs recovered with spermatozoa on the zona pellucida and the type of semen: frozen, $0.8 \times 10^{9}$, $22.2 \%$; frozen, $1.6 \times 10^{9}, 37.5 \%$; fresh, $1.6 \times 10^{9}, 62.5 \%$.

\section{EXPERIMENT 3}

The effects of type of semen (fresh versus frozen) and of concentration of motile spermatozoa in frozen semen on the distribution of spermatozoa throughout the genital tract of ewes 30 min after insemination were examined in Exp. 3.

There were four treatment groups, each of eight animals; $N=32$;

(1) - Frozen semen, $0.2 \times 10^{9}$ motile spermatozoa $/ \mathrm{ml}$

(2)-Frozen semen, $0.6 \times 10^{9}$ motile spermatozoa $/ \mathrm{ml}$

(3) 一Frozen semen, $1.8 \times 10^{9}$ motile spermatozoa $/ \mathrm{ml}$

(4) - Fresh semen, $1.8 \times 10^{9}$ motile spermatozoa/ml

Each ewe was inseminated once (cervical insemination) with $0.1 \mathrm{ml}$ of semen, 1 to $16 \mathrm{hr}$ after the onset of oestrus.

Vagina. The mean numbers of spermatozoa found in the cranial vagina were $7 \cdot 1,32 \cdot 1,73 \cdot 7$ and $55 \cdot 2$ million for Treatments 1 to 4 and in each treatment represented approximately $20 \%$ of the total number inseminated (motile+ non-motile). Some spermatozoa may have remained in the caudal vagina, which was not examined, but most of the loss was probably attributable to the drainage and/or expulsion of mucus with spermatozoa from the vagina between insemination and slaughter.

Cervix. The mean numbers for the caudal, mid and cranial regions of the cervix are shown in Table 4 . The number increased as the concentration of spermatozoa in the frozen semen increased from 0.2 to $1.8 \times 10^{9}$ motile cells/ $\mathrm{ml}(\boldsymbol{P}<0.001)$, and insemination with fresh semen resulted in markedly higher numbers than with frozen semen $(P<0.01)$, even with equivalent concentrations of motile spermatozoa. 


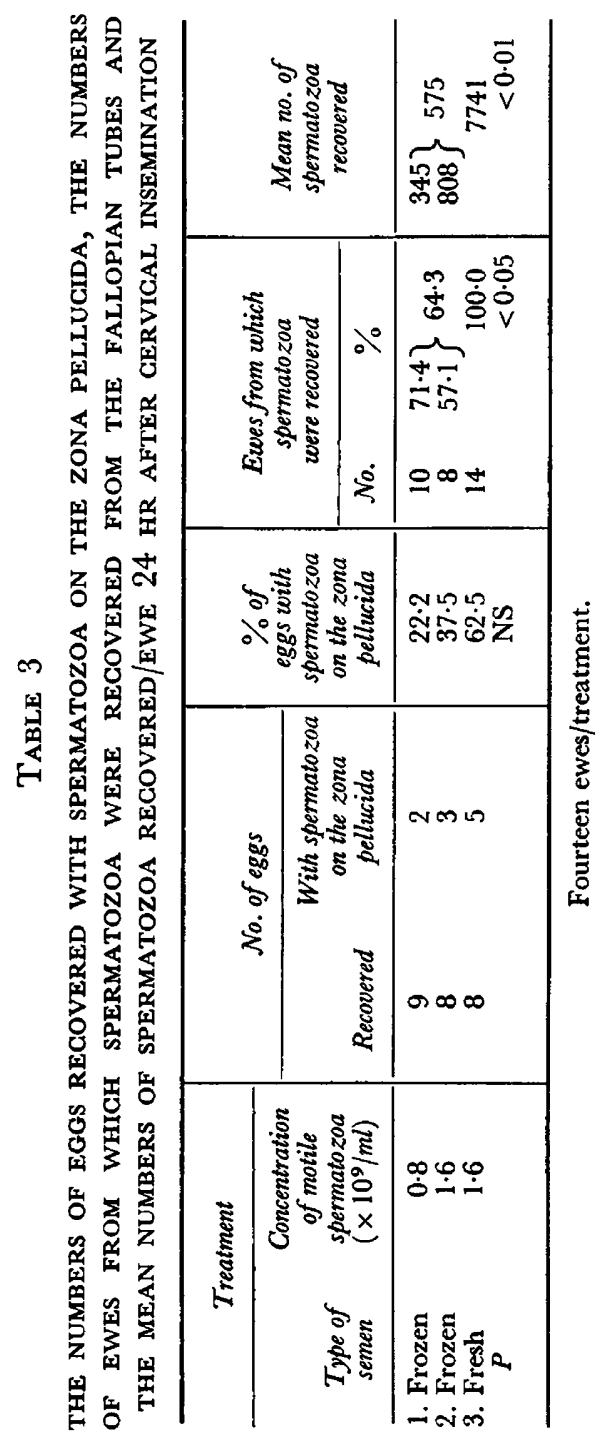


There was a highly significant linear decline in the numbers of spermatozoa recovered from the caudal to the cranial region $(P \ll 0 \cdot 001)$ and there was no interaction between region and semen treatment, indicating that the rate of progression along the cervix, although variable, was similar in all treatments. However, the variability between ewes increased as spermatozoa were recovered from increasingly cranial regions of the cervix, as shown by the decreasing levels of significance of the regressions of the number of spermatozoa recovered on concentration of frozen semen (caudal, $P<0.001$; mid, $P<0.05$; cranial,

TABLE 4

THE EFFECTS OF TYPE OF SEMEN (FRESH VERSUS FROZEN) AND OF CONCENTRATION OF MOTILE SPERMATOZOA IN FROZEN SEMEN ON THE MEAN NUMBERS OF SPERMATOZOA RECOVERED FROM THE CERVIX OF EWES 30 MIN AFTER INSEMINATION

\begin{tabular}{|c|c|c|c|c|c|}
\hline \multirow{2}{*}{\multicolumn{2}{|c|}{ Treatment }} & \multicolumn{4}{|c|}{ No. of spermatozoa $\left(\times 10^{6}\right)$} \\
\hline & & \multicolumn{3}{|c|}{ Region of cervix } & \multirow[b]{2}{*}{$\begin{array}{l}\text { Total } \\
\text { cervix }\end{array}$} \\
\hline $\begin{array}{l}\text { Type of } \\
\text { semen }\end{array}$ & $\begin{array}{c}\text { Conc. }\left(\times 10^{9} \text { motile }\right. \\
\text { spermatozoa } / \mathrm{ml})\end{array}$ & Caudal & Mid & Cranial & \\
\hline $\begin{array}{l}\text { 1. Frozen } \\
\text { 2. Frozen } \\
\text { 3. Frozen } \\
\text { 4. Fresh }\end{array}$ & $\begin{array}{l}0.2 \\
0.6 \\
1.8 \\
1.8\end{array}$ & $\begin{array}{l}0.122 \\
0.448 \\
1.241 \\
7.031\end{array}$ & $\begin{array}{l}0.005 \\
0.039 \\
0 \cdot 103 \\
0.537\end{array}$ & $\begin{array}{l}0.003 \\
0.002 \\
0.008 \\
0.042\end{array}$ & $\begin{array}{l}0.130 \\
0.489 \\
1.352 \\
7 \cdot 610\end{array}$ \\
\hline Means & & $2 \cdot 211$ & 0.171 & 0.014 & $2 \cdot 396$ \\
\hline
\end{tabular}

Summary of analysis of variance of the data in Table 4

\begin{tabular}{|c|c|c|c|c|}
\hline \multicolumn{2}{|l|}{ Source of variation } & d.f. & Mean square & Variance ratio \\
\hline $\begin{array}{l}\text { Semen treatment } \\
\text { Fresh versus frozen semen } \\
\text { Concentration of spermatozoa in frozer }\end{array}$ & 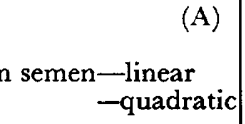 & $\begin{array}{l}1 \\
1 \\
1\end{array}$ & & $\begin{array}{l}7 \cdot 81^{* *} \\
13 \cdot 91^{* * * *} \\
0 \cdot 15\end{array}$ \\
\hline Error 1 (Ewes within semen treatments) & & 28 & 3.39 & \\
\hline Cervical segment & $\begin{array}{ll} & \text { (B) } \\
\text { linear } & \\
\text { quadratic }\end{array}$ & $\begin{array}{l}1 \\
1\end{array}$ & & $\begin{array}{l}98 \cdot 99 * * * \\
1.49\end{array}$ \\
\hline $\begin{array}{l}\mathrm{A} \times \mathrm{B} \\
\text { Error 2-Residual }\end{array}$ & & $\begin{array}{r}6 \\
56\end{array}$ & 1.74 & 1.05 \\
\hline
\end{tabular}

$$
\mathrm{n}=8 . \quad * * P<0.01 ; \quad * * * P<0.001 .
$$

$0.05<P<0.1)$. The following regression $(P<0.001)$ was calculated for total cervical spermatozoa:

$$
\begin{aligned}
\mathrm{y} & =1 \cdot 75+1 \cdot 27 \mathrm{x} \\
\text { S.E. } & =( \pm 0 \cdot 88)( \pm 0 \cdot 31)
\end{aligned}
$$

where $y=\log _{10}$ number of spermatozoa in cervix, $x=\log _{10}$ concentration of motile spermatozoa $\left(\times 10^{9}\right)$ in the inseminate (frozen semen). 


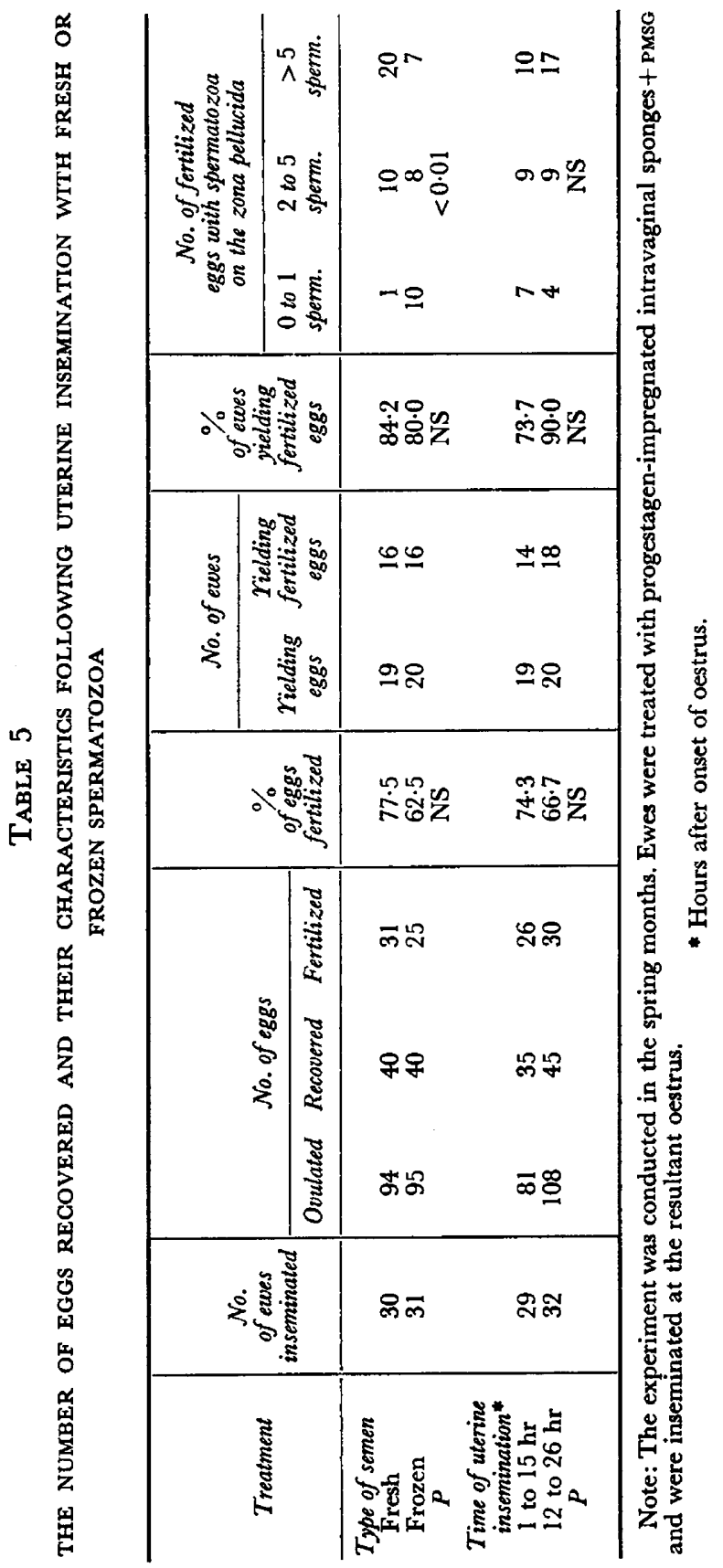


Uterus and Fallopian tubes. Spermatozoa were found in the uterine flushings of only four ewes of the thirty-two examined, two in Treatment 1 (6600 and $1,067,200$ spermatozoa) and two in Treatment 4 (300 and 69,600). Spermatozoa were found in the tubal flushings of four ewes, only two of which yielded spermatozoa from the uterus. One of these was from Treatment 1 (3620) and one from Treatment $4(20)$. The remaining two ewes were from Treatment 3 (1180 and 60).

\section{EXPERIMENT 4}

The experiment compared viability in vivo of frozen versus fresh spermatozoa as measured by the retention of fertilizing capacity following uterine insemination in (a) the spring months, using intravaginal progestagen treatment followed by PMSG and (b) in the autumn, using ewes in natural oestrus.

\section{Experiment $4 a$}

The experiment was of factorial design; $2 \times 2 ; \mathrm{n}=9$ or 10 (number of ewes from which eggs were recovered); $\mathrm{N}=39$ :

(1) Type of semen-fresh versus frozen

(2) Time of uterine insemination-1 to 15 versus 12 to $26 \mathrm{hr}$ after onset of oestrus.

All ewes were inseminated by the uterine method with $0.1 \mathrm{ml}$ of semen containing $150 \times 10^{6}$ motile spermatozoa.

The results are presented in Table 5. Neither type of semen nor time of uterine insemination had a significant effect on the percentage of eggs recovered, eggs fertilized or ewes yielding fertilized eggs. Owing to the high dose of PMSG administered (see Materials and Methods), the time of ovulation was advanced considerably relative to the onset of oestrus. Thus, ovulation had already occurred in $20 \%$ of the ewes when inseminated 1 to $15 \mathrm{hr}$ after the onset of oestrus and in $48 \%$ of ewes inseminated at 12 to $26 \mathrm{hr}$. There was no apparent effect of time of ovulation on fertilization. The use of fresh semen resulted in more eggs with large numbers of spermatozoa attached to the zona pellucida than did frozen semen $(P<0.01)$.

\section{Experiment $4 b$}

This was a simple comparison of the fertilizing capacity of fresh versus frozen spermatozoa when deposited into the uterus of ewes, in the normal breeding season, 1 to $6 \mathrm{hr}$ after the onset of oestrus. Observations made during a concomitant experiment (Exp. 2) using the same flock of ewes indicated that ovulation occurred at the normal time, approximately 24 to $36 \mathrm{hr}$ after the onset of oestrus. The uterine inseminations $\left(0 \cdot 1 \mathrm{ml}\right.$ containing $160 \times 10^{6}$ motile spermatozoa) were therefore performed approximately 18 to $35 \mathrm{hr}$ before ovulation.

Ten ewes were inseminated with fresh and nine with frozen semen, and one egg was recovered from each of eight and six ewes, respectively. All eggs were fertilized and showed normal cell cleavage. 


\section{DISCUSSION}

The importance of the cervix in the physiology of the transport of ovine spermatozoa has been well established (Quinlan, Maré \& Roux, 1933; Starke, 1949; Dauzier \& Wintenberger, 1952a; Dauzier, 1953; Mattner \& Braden, 1963; Mattner, 1963, 1966). It constitutes the first barrier to the transport of spermatozoa through the genital tract, provides favourable environmental conditions for survival and acts as a reservoir from which spermatozoa continuously progress to the site of fertilization. The results reported here show the importance of two aspects involving the cervix in the failure of transport of spermatozoa following insemination with frozen semen. These are, first, the initial entry of spermatozoa into the cervix following insemination; and second, the viability of the spermatozoa in vivo which is associated with the maintenance of the cervical population.

Concerning the initial entry of spermatozoa into the cervix, the most significant observation was that the establishment of a cervical population was directly related to the concentration of motile spermatozoa in the inseminate (Exp. 3). It is possible that at very low concentrations the influence of dilution may be of more importance than the effects of freezing and thawing. Thus in Exp. 1, although insemination with frozen semen of low concentration resulted in the recovery of few spermatozoa from the Fallopian tubes, fresh semen, when diluted to the same low concentration of motile spermatozoa, produced equally poor results although the fertilization rate was higher. The results suggest that, for artificial insemination, the concentration of motile spermatozoa in the inseminate should be as high as possible, probably in the vicinity of $2 \cdot 0 \times 10^{9} / \mathrm{ml}$. With ram semen frozen by the pellet method, this necessitates centrifugation immediately after thawing, as the use of very low dilution rates both before freezing and at thawing is associated with low revival rates and subsequent poor viability of the thawed spermatozoa (Lightfoot \& Salamon, 1969a, b).

Following the establishment of the cervical population, the viability of frozen ram spermatozoa in vivo may be lower than that for fresh spermatozoa. Thus, Loginova \& Zeltobrjuk (1968) reported that the viability of frozen spermatozoa in the ewe's genital tract after cervical insemination was only 12 $\mathrm{hr}$, and fertilizing capacity was retained for no longer than $9 \mathrm{hr}$. More recently, Mattner et al. (1969) have attributed to reduced viability the low numbers of spermatozoa they found throughout the genital tract after insemination with frozen, compared with fresh, semen. Although their result may have been due in part to the lower concentration of motile spermatozoa in the frozen semen, it seems likely that the spermatozoa were less viable than those frozen rapidly by the pellet method and used in the experiments reported here. Hence, Mattner et al. (1969) found no spermatozoa in the Fallopian tubes $24 \mathrm{hr}$ after insemination as compared with means of 92 and 808 spermatozoa from comparable treatments of Exps 1 and 2 reported here.

Further, the results of Exp. 4b show that a proportion of the pellet-frozen spermatozoa survived in the ewe's genital tract and retained the capacity to fertilize eggs for approximately 18 to $35 \mathrm{hr}$, compared with estimates of approximately 48 and $30 \mathrm{hr}$ reported by Green (1947) and Dauzier \& Wintenberger 
(1952b) respectively for fresh spermatozoa. It should be noted, however, that Exp. 4b involved uterine insemination, by which means comparatively large numbers of spermatozoa can be established in the cervix (Lightfoot \& Restall, unpublished). With normal cervical insemination and consequently fewer spermatozoa in the tract, the problem of low viability may assume added significance.

There are reports in several species, including swine (Milovanov \& Sergeev, 1961; Jarosz, 1966) and cattle (Hays \& VanDemark, 1952; Rowson, 1955; VanDemark \& Hays, 1955), which indicate that the administration of oxytocin may increase the rate of transport of spermatozoa through the female genital tract. Published work with ewes is limited. Thibault \& Wintenberger-Torres (1967) injected ewes with oxytocin (1.0 i.u., i.v.) after $30 \mathrm{~min}$ of unrestrained mating, but found no evidence for an increased rate of transport. However, Lang \& Oh (1968) claimed that whereas injections of 0.1 i.u. had no effect, 1.0 i.u. depressed the numbers of spermatozoa recovered from the Fallopian tubes $16 \mathrm{hr}$ after mating. The high doses (10 and $20 \mathrm{i} . \mathrm{u}$.) used in the present study did not affect the number of spermatozoa recovered from the Fallopian tubes, but such treatment significantly depressed fertility - an effect which has been confirmed in subsequent experiments (Salamon \& Lightfoot, 1970).

In conclusion, it appears that the low fertilization rate obtained following insemination with pellet-frozen ram semen is due to the failure in the normal pattern of transport and consequently low numbers of motile spermatozoa in the genital tract of the ewe. Embryonic mortality following cervical insemination with pellet-frozen ram semen is of a similar magnitude to that found with fresh semen(Lightfoot \& Salamon, 1970). Therefore, procedures that effectively aid the initial establishment of the cervical population of spermatozoa, such as increasing the concentration of motile spermatozoa in the thawed semen and double insemination, result in improved lambing performance (Salamon \& Lightfoot, 1970).

\section{ACKNOWLEDGMENTS}

The authors are indebted to Mr J. L. Hodgkinson and Sons, Vale View, Yass, N.S.W., for their generous provision of sheep and facilities in Experiment 4, to $\mathrm{Mr} \mathrm{B}$. M. Bindon for conducting PMSG assays, and to Sandoz Australia Pty Ltd for donations of oxytocin.

We wish to thank Professor T. J. Robinson for his comments on the manuscript.The research was aided by grants from the Australian Wool Board and the Australian Research Grants Committee.

\section{REFERENCES}

Claringbold, P. J. (1961) The use of orthogonal polynomials in the partition of chi-square. Aust. $\mathcal{F}$. Statistics, 3, 48 .

Dauzier, L. (1953) Recherches sur les facteurs de la remontée des spermatozoides dans les voies génitales femelles. Étude chez la brebis (col de l'utérus). C. r. Séanc. Soc. Biol. 147, 1556.

Dauzier, L. \& Wintenberger, S. (1952a) La vitesse de remontée des spermatozoides dans le tractus génital de la brebis. Annls Zootech. 1, 13.

DAUZIER, L. \& Wintenberger, S. (1952b) Recherches sur la fécondation chez les mammifères: Durée du pouvoir fécondant des spermatozoïdes de bélier dans le tractus génital de la brebis et durée de la période de fécondité de l'œuf après 'olvulation. C. r. Séanc. Soc. Biol. 146, 660. 
Fmmens, C. W. (1961) Dilution, transport and storage of ram semen. In: Artificial Breeding of Sheep in Australia, p. 118. Proc. Conf. School of Wool Technology, University of N.S.W., Australia.

Emmens, C. W. \& Robinson, T. J. (1962) Artificial insemination in the sheep. In: The Semen of Animals and Artificial Insemination. Tech. Commun. Commonw. Bur. Anim. Breed. Genet. 15, 205.

Green, W. W. (1947) Duration of sperm fertility in the ewe. Am. F. vet. Res. 8, 299.

Hackett, A. J. \& Macpherson, J. W. (1965) Some staining procedures for spermatozoa. A review. Can. vet. 7. 6, 55.

Hays, R. L. \& VANDemark, N. L. (1952) The effect of hormones on uterine motility and sperm transport in the perfused genital tract of the cow. 7. Dairy Sci. 35, 499.

Jarosz, S. (1966) The effect of hypophysin introduced into the uterus on sperm transport in the uterus and oviducts of the sow. Roczn. Nauk. roln. Ser. B, 88, 19. (Anim. Breed. Abstr. 36, No. 604).

LANG, D. R. \& OH, K. Y. (1968) Distribution of spermatozoa in the reproductive tract of the Romney ewe. Proc. N.Z. Soc. Anim. Prod. 28, 120.

Lightfoot, R. J. Salamon, S. (1969a) Freezing ram spermatozoa by the pellet method. II. The effects of method of dilution, dilution rate, glycerol concentration and duration of storage at $5^{\circ} \mathrm{C}$ prior to freezing on survival of spermatozoa. Aust. F. biol. Sci. 22, 1547.

Lightfoot, R. J. \& Salamon, S. (1969b) Freezing ram spermatozoa by the pellet method. III. The effects of pellet volume, composition of the thawing solution and reconcentration of the thawed semen on survival of spermatozoa. Aust. 7. biol. Sci. 22, 1561.

Lightfoot, R. J. \& Salamon, S. (1970) Fertility of ram spermatozoa frozen by the pellet method. II. The effects of method of insemination on fertilization and embryonic mortality. 7. Reprod. Fert. 22, 399.

Loginova, N. V. (1962) Causes of low fertility in ewes inseminated with frozen semen. Ovtsevodstvo, $8(8), 20$.

Loginova, N. V. \& Zeltobrjuk, N. A. (1968) Test of different methods of freezing semen. Ovtsevodstvo, 14(9), 22.

Lopyrin, A. I. \& Loginova, N. V. (1958) Method of freezing ram semen. Ovtsevodstvo, 4(8), 31.

Matrner, P. E. (1963) Spermatozoa in the genital tract of the ewe. II. Distribution after coitus. Aust. 7. biol. Sci. 16, 688 .

Mattner, P. E. (1966) Formation and retention of the spermatozoan reservoir in the cervix of the ruminant. Nature, Lond. 212, 1479.

Mattner, P. E. \& BRAden, A. W. H. (1963) Spermatozoa in the genital tract of the ewe. I. Rapidity of transport. Aust. F. biol. Sci. 16, 473.

Matrner, P. E. Entwistle, K. W. \& Martin, I. G. A. (1969) Passage, survival and fertility of deepfrozen ram semen in the genital tract of the ewe. Aust. F. biol. Sci. 22, 181.

Milovanov, V. K. \& Sergeev, N. I. (1961) The simultaneous use of oxytocin-a new method of increasing the effectiveness of artificial insemination of pigs. Zhivotnovodstvo, Mosk. 23(11), 70.

Quinlan, J., Mart, G. S. \& Roux, L. L. (1933) A study of the duration of motility of spermatozoa in the different divisions of the reproductive tract of the Merino sheep. Onderstepoort 7. vet. Res. 1, 135.

Quinlivan, T. D. \& Robinson, T. J. (1967) The number of spermatozoa in the fallopian tubes of ewes at intervals after artificial insemination following withdrawal of SC-9880-impregnated intravaginal sponges. In: The Control of the Ovarian Cycle in the Sheep, p. 177. Ed. T. J. Robinson. Sydney University Press.

Radford, H. M., Watson, R. H. \& Wood, G. F. (1960) A crayon and associated harness for the detection of mating under field conditions. Aust. vet. $7.36,57$.

RoBinson, T.J. (1965) Use of progestagen-impregnated sponges inserted intravaginally or subcutaneously for the control of the oestrous cycle in the sheep. Nature, Lond. 206, 39.

Rowson, L. E. A. (1955) The movement of radio opaque material in the bovine uterine tract. Br. vet. $\mathcal{J}$. $111,334$.

SAdleir, R. M. F. S. (1966) The preservation of mammalian spermatozoa by freezing. Lab. Pract. 15, 413.

Salamon, S. \& Lightfoot, R. J. (1967) Fertilisation and embryonic loss in sheep after insemination with deep frozen semen. Nature, Lond. 216, 194.

Salamon, S. \& Lightfoot, R. J. (1970) Fertility of ram spermatozoa frozen by the pellet method. III. The effects of insemination technique, oxytocin and relaxin on lambing. 7. Reprod. Fert. 22, 409.

Starke, N. G. (1949) The sperm picture of rams of different breeds as an indication of their fertility. II. The rate of sperm travel in the genital tract of the ewe. Onderstepoort $\mathbf{J}$. vet. Res. 22, 415.

Thibault, C. \& Wintenberger-Torres, S. (1967) Oxytocin and sperm transport in the ewe. Int. $\mathcal{F}$. Fert. 12, 410 .

VanDemark, N. L. \& Hays, R. L. (1955) Sperm transport in the perfused genital tract of the cow. Am. J. Physiol. 183, 510. 